\title{
Aetiological profile of global developmental delay in children under 5 years of age: experience from a tertiary referral centre
}

\author{
*Jayasuriya Mudiyanselage Udara Amawasi Bandara ${ }^{1}$, Jagath Munasinghe ${ }^{1}$
}

Sri Lanka Journal of Child Health, 2020; 49(4): 361-368

\begin{abstract}
Introduction: Global developmental delay (GDD) is a common paediatric condition with an estimated prevalence of $1-3 \%$. Aetiological diagnosis assists in preventive strategies, prognosis, assessing recurrent risk and treatment.
\end{abstract}

Objectives: To describe the aetiological profile of GDD, to identify preventable causes and to determine the percentage of undetermined aetiology.

Method: A descriptive study was conducted over a period of 5 months in a paediatric neurology clinic at a tertiary referral centre which included children with GDD below the age of 5 years. Interviewer administered standardised questionnaire was used to collect demographic data, while clinical data, examination and investigation results were extracted from the neonatal and neurology clinic records.

Results: A total of 185 patients met the inclusion criteria (female: male ratio 1:1.4). Mean age at recognition of GDD was $15.2 \pm 1.99$ months. An aetiological diagnosis was determined in 108 (58.4\%), which was categorized under hypoxic ischaemic encephalopathy (HIE) $(n=51,27.6 \%)$, structural brain abnormalities $(n=28,15.1 \%)$, post infectious $(\mathrm{n}=13,7.0 \%)$, genetic/chromosomal $(n=7,3.8 \%)$, embryo-fetopathy $(n=5,2.7 \%)$ and hypothyroidism $(n=3,1.6 \%)$. Aetiology was undetermined with the available clinical details and investigation results in $62(33.5 \%)$. A possible diagnosis of genetic/chromosomal origin was suspected in $11(5.9 \%)$ and a possible diagnosis of an inborn error of metabolism was suspected in 4 $(2.2 \%)$ from historical and examination findings.

\footnotetext{
${ }^{1}$ Sirimavo Bandaranaike Specialized Children's Hospital, Sri Lanka

*Correspondence: amawasi80@yahoo.com$$
\text { iD. }
$$$$
\text { orcid.org/ 0000-0003-3677-8028 }
$$

(Received on 26 November 2019: Accepted after revision on 24 January 2020)

The authors declare that there are no conflicts of interest

Personal funding was used for the project.

Open Access Article published under the Creative

Commons Attribution CC-BY (cC) (P)
Conclusions: In the paediatric neurology clinic at the tertiary referral centre, HIE, structural brain abnormalities, post infectious, genetic/ chromosomal, embryo-fetopathy and hypothyroidism were the identified causes of GDD. Aetiology was undetermined with the available clinical details and investigation results in $33.5 \%$.

DOI: http://dx.doi.org/10.4038/sljch.v49i4.9272

(Key words: Global developmental delay, paediatrics, paediatric neurology, aetiological profile, aetiological yield, Sri Lanka)

\section{Introduction}

Global developmental delay (GDD) is a relatively common paediatric condition and its prevalence is estimated to be $1-3 \%{ }^{1}$. GDD is defined as significant delay (2 SD below the age appropriate mean) in 2 or more developmental domains including gross or fine motor, speech/language, cognitive, social/personal, and activities of daily living in children younger than 5 years of age ${ }^{2}$. The presence of GDD is thought to predict a future diagnosis of intellectual disability ${ }^{3}$, which is defined as an intelligence quotient (IQ) of below 70 at the age of 5 years or older ${ }^{4}$. In 2011, the World Health Organisation (WHO) International Classification of Diseases (ICD) Working Group on the Classification of Intellectual Disabilities proposed the term intellectual developmental disorders (IDD) to include a group of developmental conditions characterized by significant impairment of cognitive functions associated with limitation of learning, adaptive behaviour and life skills ${ }^{5}$. IDD comprises both intellectual disability and GDD in the respective age groups and is associated with the highest lifetime health care and economic costs of any disease, nearly equalling the economic impact of stroke, heart disease and cancer combined ${ }^{6}$.

Aetiologies of GDD includes genetic, metabolic, structural abnormalities of the brain, infections, complicated birth history (maternal pre-eclampsia, infectious embryo-fetopathy, prematurity, birth asphyxia, low birth weight, neonatal sepsis, kernicterus), endocrine disorders and exposure to environmental toxins ${ }^{3,7-12}$ to name a few. Arriving at an aetiological diagnosis would assist in predicting the prognosis, assessing the recurrence risk in future pregnancies, provision of refined 
treatment options, avoiding unnecessary investigations, surveillance of known complications, parental counselling and overall improvement in the psycho-social outcome of both affected children and their families ${ }^{1}$. A Sri Lankan study by Perera $\mathrm{H}$, in 2005 to assess the developmental readiness for school entry at 5 years, detected a delayed cognitive development in $17.8 \%{ }^{13}$. This highlights the importance of early detection and intervention, aiming at improving the neuro-developmental outcome. Currently, there is a paucity of published data on prevalence of aetiologies of developmental delay in Sri Lanka.

\section{Objectives}

The main objective of the study was to evaluate the aetiological profile of GDD in children under the age of 5 years presenting to a tertiary care referral centre. Further objectives included determining the percentage of children with GDD of 'undetermined aetiology' after the clinical evaluation and available investigations and describing GDD in relation to maternal, post-natal and early childhood causative factors.

\section{Method}

A descriptive study was conducted at the Paediatric Neurology Clinic at the Sirimavo Bandaranayake Specialised Children's Hospital, Peradeniya to describe the aetiological profile of GDD in children under five years of age. All children with GDD who were under the age of 5 years at the time of diagnosis and attending the clinic between $1^{\text {st }}$ of March 2019 and $30^{\text {th }}$ of August 2019 were included in the study. The sample included children registered in the clinic from July 2013 to $30^{\text {th }}$ of August 2019. Children who were above the age of 5 years at the time of diagnosis of GDD, children diagnosed with isolated developmental disorders such as Autistic Spectrum Disorders, attention deficit hyperactivity disorder (ADHD), children with isolated speech delay and children with isolated neuromuscular disorders were excluded. All patients attending the paediatric neurology clinic have been evaluated, including developmental assessment by the Consultant Paediatric Neurologist. A diagnosis of GDD was made when a significant delay in 2 or more developmental domains was detected in a child under the age of 5 years.

In this clinic setting, neuroimaging, either computed tomography (CT) or magnetic resonance imaging (MRI) of brain, depending on the clinical indication and availability, is performed as a routine test in children with GDD to support the aetiological diagnosis. Electroencephalography (EEG) is performed in patients with clinical features of epilepsy and epilepsy syndromes as per recommendations of the American Academy of
Neurology $y^{3}$ and also in GDD of undetermined aetiology. Karyotyping and some genetic studies are performed in patients with suspected genetic syndromes. Metabolic screening is offered to those who have compatible history. Patients with unexplained GDD or having $\mathrm{CT}$ evidence of congenital infections undergo TORCH screening.

An interviewer administered standardised questionnaire was used to obtain demographic data from the parent/guardian. The demographic data included the age, gender, geographical region (district lived during pregnancy and district lived during the first 2 years of life), parents' occupation and level of education and maternal habits (alcohol, tobacco and substance abuse). Parents' occupation was categorized into occupation groups as per guidelines published in the Labour Demand Survey ${ }^{14}$. Consanguinity and family history of developmental delay were also obtained during the interview. The rest of the clinical data, examination and investigation results were extracted from the patient's neonatal records and neurology clinic records. The data obtained from the medical records included, the age of onset of developmental delay, presence of dysmorphic features, antenatal history (TORCHS, maternal pre-eclampsia, antepartum haemorrhage, maternal exposure to drugs, alcohol, smoking), perinatal history (birth asphyxia, Apgar score, prematurity, intrauterine growth retardation, birth trauma), postnatal (kernicterus, seizures, hypoglycaemia, meningitis, sepsis) and results of the investigations performed for diagnosis such as CT/MRI/EEG/ karyotyping/ genetic studies/ metabolic screening and TORCH screening.

The aetiological diagnosis was categorized under the following:

1. Diagnosis confirmed - Embryo-fetopathy, hypoxic ischaemic encephalopathy (HIE), post infectious (encephalitis/ meningitis), genetic or chromosomal defects, hypothyroidism, kernicterus, inborn errors of metabolism (IEM), structural brain abnormalities

2. Possible genetic aetiology

3. Possible metabolic aetiology

4. Undetermined

The diagnosis of HIE was based on the diagnosis given in the neonatal records (supported by Apgar score when available) or based on the clinical history of birth asphyxia and evidence from changes in CT/MRI brain supporting a diagnosis of HIE.

\section{Results}

Age at recognition of GDD and socio-demographic profile of the study population 
The sample consisted of 185 subjects who met the inclusion and exclusion criteria. The mean age at the time of the study was $73.8 \pm 6.1$ months (age range 8 months to 15 years). Seventy seven $(41.6 \%)$ were female while 108 (58.4\%) were male, giving a sex ratio of 1:1.4.
Age at recognition of GDD ranged from birth to 56 months, with a mean age of $15.2 \pm 1.99$ months. Highest frequency of age at recognition of GDD in the study group was below 3 months of age $(n=27$, $14.6 \%)$, of which $17(9.1 \%$ of total sample) were noted to have GDD since birth. (Figure 1)

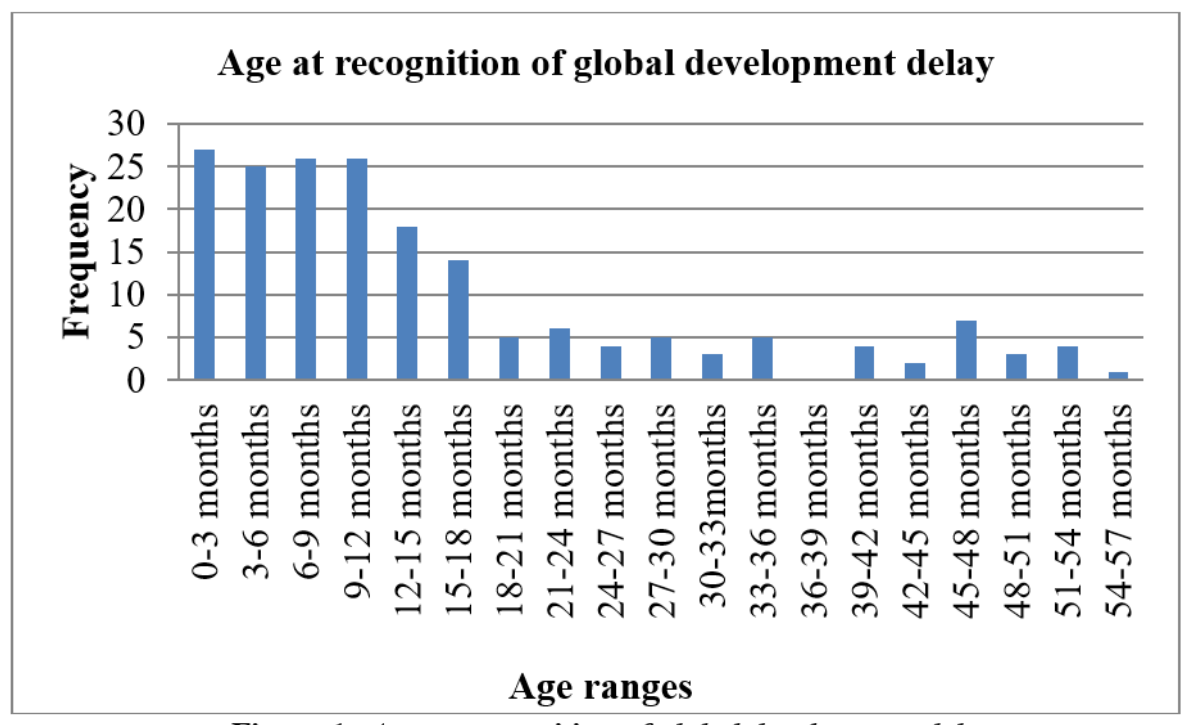

Figure 1: Age at recognition of global development delay

Majority $(36.8 \%, n=68)$ of patients had lived in Kandy district during pregnancy. Majority (95.7\%) had remained in the same district during the first 2 years after birth, of whom $61 \%$ were from the Central Province, $12.4 \%$ from Sabaragamuwa Province, $11.4 \%$ from Uva Province, $6.4 \%$ from North Western Province and 3.7\% from North Central Province. The remainder were from
Western $(2.1 \%)$, Eastern $(2.2 \%)$ and Southern Provinces $(0.5 \%)$.

Most mothers had Ordinary Level qualifications $(40 \%, n=74)$, and $8.1 \% \quad(n=15)$ had completed tertiary level. The most common level of education among fathers was Ordinary Level $(38.4 \%, \mathrm{n}=71)$ while $4.3 \% \quad(n=8)$ had completed tertiary level (Figure 2).

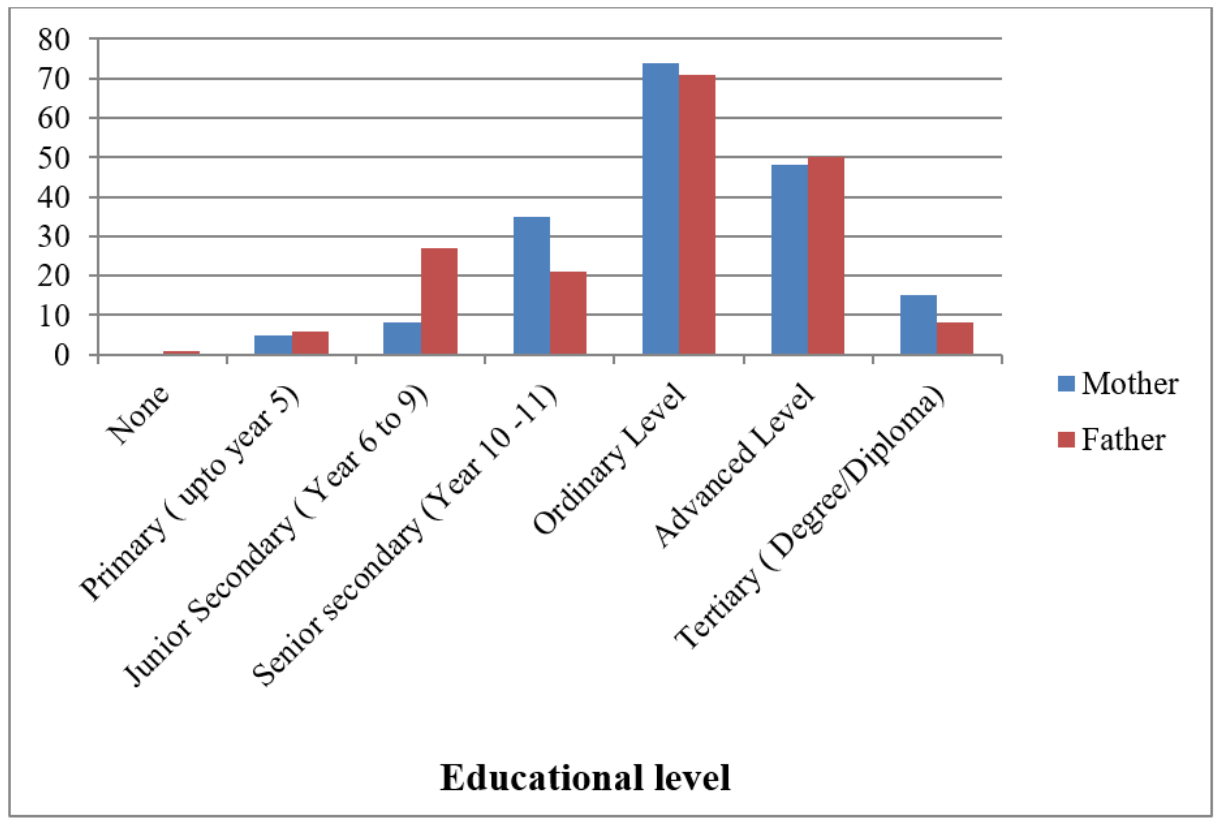

Figure 2: Educational level of parents 
Most common occupational category among mothers was Service and Sales worker $(87 \%$, $\mathrm{n}=161)$, which included the position of housewife $(85.4 \%, n=158)$, while $9(4.7 \%)$ were employed as professionals. Sixty (32.4\%) fathers were employed as Service and Sales workers, while $3(1.6 \%)$ were professionals and $3(1.6 \%)$ were unemployed.

\section{Predisposing factors for GDD}

Almost all mothers $(\mathrm{n}=184,99.5 \%)$ denied using alcohol, tobacco or recreational drugs during pregnancy. Maternal habits were unknown in one subject who was adopted. History of consanguinity was present in $18(9.7 \%)$ and $10(5.4 \%)$ had a family history of developmental delay. History of consanguinity and family history of developmental delay was unknown in one patient who was adopted. An antenatal history of TORCHS infection was present in $1.1 \%(n=2)$. In this study group $37(20 \%)$ had a maternal history of miscarriage in a previous pregnancy and $4(2.2 \%)$ had an antenatal history of threatened miscarriage. A total of $32(17.3 \%)$ patients had a history of birth asphyxia and $32(17.3 \%)$ were premature at birth. Out of the premature babies only $9(4.9 \%)$ had a history of birth asphyxia. Fifty six (30.2\%) had a history of neonatal seizures. During the neonatal period, $52(28.1 \%)$ were treated for suspected sepsis. The results of blood cultures were not available in the clinic records to further analyse the significance of this finding. Only one patient had a history of kernicterus. Three patients had history of late onset meningitis, age of onset at 5 months, 6 months and 2 years respectively (Table 1).

\section{Investigations performed to diagnose aetiology of $G D D$}

Majority of patients $(\mathrm{n}=156,84.3 \%)$ had undergone EEG, while $94.6 \%(n=175)$ had undergone either CT or MRI. CT of the brain was performed in 129 (69.7\%) and MRI was performed in 92 (49.7\%). Twenty patients $(10.8 \%)$ have had TORCHS screening performed postnatally. The decision to screen for congenital infection was based on the clinical features and CT/MRI findings. Two patients were screened postnatally purely due to a positive maternal TORCHS screening. (Table 2)

Sixteen (8.6\%) patients had undergone metabolic screening which included thyroid function tests, serum lactate level, urine organic acids, urine mucopolysaccharide levels, amino acid profile and cerebrospinal fluid (CSF) glucose levels.
Table 1

Predisposing factors for global developmental delay

\begin{tabular}{|l|c|}
\hline Predisposing factor & $\begin{array}{c}\text { Frequency } \\
\text { (\%) }\end{array}$ \\
\hline Antenatal & $0(0)$ \\
\hline $\begin{array}{l}\text { Maternal use of alcohol/ } \\
\text { tobacco or recreational drugs }\end{array}$ & $02(01.1)$ \\
\hline TORCHS infection & $04(02.2)$ \\
\hline Pre-eclampsia & $08(04.3)$ \\
\hline Antepartum haemorrhage & \\
\hline Perinatal & $32(17.3)$ \\
\hline History of birth asphyxia & $32(17.3)$ \\
\hline Prematurity & $15(08.1)$ \\
\hline Intrauterine growth retardation & $06(03.2)$ \\
\hline Risk factors for birth trauma & $01(0.5)$ \\
\hline \multicolumn{1}{|c|}{ Cord prolapse } & $03(01.6)$ \\
\hline Obstructed labour & $01(0.5)$ \\
\hline \multicolumn{1}{|c|}{ Cord round neck } & $01(0.5)$ \\
\hline Unspecified & $01(0.5)$ \\
\hline Postnatal & $56(30.3)$ \\
\hline Kernicterus & $19(10.3)$ \\
\hline Neonatal seizures & $10(05.4)$ \\
\hline Neonatal hypoglycaemia & $52(28.1)$ \\
\hline Neonatal meningitis & $03(01.6)$ \\
\hline Treated for suspected sepsis & \\
\hline Meningitis - late onset & \\
\hline
\end{tabular}

Table 2

Investigations performed for diagnosis of aetiology of global development delay

\begin{tabular}{|l|c|}
\hline Investigation & $\begin{array}{c}\text { Frequency } \\
(\mathbf{\%})\end{array}$ \\
\hline Computed tomography of brain & $129(69.7)$ \\
\hline $\begin{array}{l}\text { Magnetic resonance imaging of } \\
\text { brain }\end{array}$ & $92(49.7)$ \\
\hline Electroencephalography & $156(84.3)$ \\
\hline Karyotyping & $13(07.0)$ \\
\hline Genetic testing & $07(03.8)$ \\
\hline Metabolic screening & $16(08.6)$ \\
\hline TORCH screening (Post-natal) & $20(10.8)$ \\
\hline
\end{tabular}

Diagnostic yield and aetiological diagnosis

A definitive aetiological diagnosis was determined in $58.4 \%(n=108)$. The commonest cause for GDD in this study group was HIE $(n=51,27.6 \%)$ followed by structural brain abnormalities $(\mathrm{N}=28$, $15.1 \%)$, post infectious $(\mathrm{n}=13, \quad 7.0 \%)$, genetic/chromosomal $(\mathrm{n}=7,3.8 \%)$, embryofetopathy $(n=5,2.7 \%)$ and hypothyroidism $(n=3$, $1.6 \%)$. Among the 32 preterm deliveries $20(62 \%$ of all preterm) were diagnosed with HIE. 
Aetiology was undetermined with the available clinical details and investigation results in 33.5\% $(\mathrm{n}=62)$. A possible diagnosis of genetic/chromosomal origin was suspected in 5.9\% $(n=11)$ from historical and examination findings and were awaiting genetic studies for confirmation. Historical and physical examination findings were suggestive of a possible diagnosis of an inborn error of metabolism (IEM) in $2.2 \%(n=4)$ out of which 3 were awaiting metabolic screening and one subject had inconclusive results following full screening. (Table 3). Aetiological yield from history and examination alone was $25.4 \%(n=47)$. $\mathrm{CT} / \mathrm{MRI}$ imaging alone provided a definitive diagnosis in $28(15.1 \%)$ and provided supportive evidence in arriving at a diagnosis in $88(47.6 \%)$ where a diagnosis was suspected from history, physical examination and other investigations.

Table 3

Aetiological diagnosis of global development delay $(n=185)$

\begin{tabular}{|l|c|}
\hline \multicolumn{1}{|c|}{ Diagnosis } & Frequency (\%) \\
\hline Embryo-fetopathy & $05(02.7)$ \\
\hline $\begin{array}{l}\text { Hypoxic ischaemic } \\
\text { encephalopathy }\end{array}$ & $51(27.6)$ \\
\hline $\begin{array}{l}\text { Post Infectious (total) } \\
\text { Neonatal meningitis } \\
\text { Late onset meningitis }\end{array}$ & $13(07.0)$ \\
\hline Genetic/ chromosomal & 03 \\
\hline Hypothyroidism & $07 / 03.8)$ \\
\hline Kernicterus & $03(01.6)$ \\
\hline Structural brain abnormalities & $01(0.5)$ \\
\hline $\begin{array}{l}\text { Possible inborn errors of } \\
\text { metabolism }\end{array}$ & $28(15.1)$ \\
\hline Possible genetic & $04(02.2)$ \\
\hline Undetermined & $11(05.9)$ \\
\hline
\end{tabular}

Table 4

Distribution of genetic causes for global development delay based on clinical findings and/or investigations

\begin{tabular}{|l|c|}
\hline Genetic causes & Frequency \\
\hline Batten disease & 1 \\
\hline Tuberous sclerosis & 2 \\
\hline $47, X Y+$ mar1 & 1 \\
\hline Fragile X & 1 \\
\hline $\begin{array}{l}\text { Heterozygous variation in exon 4 } \\
\text { TUBB2D gene }\end{array}$ & 1 \\
\hline $\begin{array}{l}\text { Translocation between } \\
\text { chromosome 3 \& 18, paternal } \\
\text { inheritance }\end{array}$ & 1 \\
\hline
\end{tabular}

Table 5

Distribution of structural brain abnormalities as a cause for global development delay

\begin{tabular}{|l|c|}
\hline Structural changes & Frequency \\
\hline Lissencephaly & 2 \\
\hline Low grade glioma & 1 \\
\hline polymicrogyria/polygyric changes & 2 \\
\hline Mega cisterna magna & 1 \\
\hline Cortical malformations & 1 \\
\hline Occipital gliosis & 1 \\
\hline Colpocephaly & 1 \\
\hline Holoprocencephaly & 2 \\
\hline Hippocampal sclerosis & 4 \\
\hline Schizencephaly & 3 \\
\hline Agenesis of corpus callosum & 3 \\
\hline hydrocephalus & 3 \\
\hline Hemimegalencephaly & 1 \\
\hline Delayed myelination & 2 \\
\hline Cerebral infarction & 1 \\
\hline
\end{tabular}

Table 6

Possible genetic causes for global development delay

\begin{tabular}{|l|c|}
\hline Possible genetic causes & Frequency \\
\hline Rett syndrome & 2 \\
\hline Fahr's syndrome & 1 \\
\hline Angelman syndrome & 1 \\
\hline Sturge weber syndrome & 1 \\
\hline Cornelia de Lange & 1 \\
\hline Pierre Robin sequence & 1 \\
\hline Dysmorphism (unclassified) & 1 \\
\hline History of consanguinity & 2 \\
\hline Mitochondrial disease & 1 \\
\hline
\end{tabular}

\section{Discussion}

The aetiological yield of this study $(58.4 \%)$ is lower but closer to the findings from a North American study and a Turkish study which reported aetiological yields of $63.3 \%{ }^{15}$ and $64 \%{ }^{16}$ respectively. Koul et al. reported a higher yield of $71.8 \%$ in Oman where metabolic screening was the second highest investigation requested, with a positive result of $12.5 \%{ }^{18}$. This may have added to the higher aetiological yield in comparison to our resource limited setting. The percentage of undetermined aetiology (33.5\%) was less than the study by Ozmen et al $(36 \%)^{16}$, as we had further categorized into possible genetic and possible IEM disease. Finding of HIE, structural brain abnormalities, genetic/chromosomal, endocrine and 
embryo-fetopathy as the common aetiologies of GDD was consistent with other studies ${ }^{15,17,18}$. Percentage of HIE (27.6\%) was similar in comparison to 2 previous studies in Turkey and Oman, $21 \%{ }^{16}$ and $26 \%{ }^{18}$ respectively and higher than reported by Majnemer et al $(10 \%)^{15}$, and Tikaria et al $(15 \%)^{17}$. The third common aetiology was neonatal meningitis and late onset meningitis $(\mathrm{n}=13,7.0 \%)$ which was higher than reported by Koul et al in a study which included a sample size of 110 patients $(n=1,3 \%)^{18}$. Thus there is definite room for improvement in terms of antenatal and perinatal care in preventing perinatal asphyxia and neonatal meningitis.

The purpose of evaluating the district during pregnancy and during the first 2 years of age was to gain a basic understanding of the level of routine antenatal and paediatric care available for patients. Although our sample is not representative of the entire province, it is worthwhile looking into processes of improving perinatal care in the region in order to minimise perinatal asphyxia and infection. The aetiological yield from history and examination alone in this centre was $25.4 \%$ and when combined with neuroimaging, EEG and genetic studies, the aetiological yield rose to $50.8 \%$ $(n=94)$. The majority of patients in this centre have undergone neuroimaging keeping in line with international guidelines ${ }^{3}$. The aetiological yield would further improve with the availability of genetic (Array CGH) and metabolic testing, which has become challenging in our resource limited setting.

The demographic data show that the majority of patients, as expected, were from the Kandy district in the central province due to the proximity to the tertiary centre. A small number presented from distant provinces. Since this tertiary referral centre in the central province is catering to patients from 8 out of 9 provinces in Sri Lanka, service improvement would benefit a widespread population in the country.

The study had some limitations. Since this was a retrospective study where history and examination was extracted from the clinic records, we encountered a limitation in grading of global development delay to mild, moderate and severe due to insufficient data. This study population, being the referrals in a tertiary care centre, might not represent the general population. Nevertheless, identifying preventable causes of GDD would be helpful to design neonatal screening programme for congenital infections, treatable metabolic disorders, for parent counselling. Exposure to environmental toxins has been linked to GDD in children ${ }^{3,7-12}$. However, this study did not focus on the exposure to environmental toxins (lead, mercury and pesticides) as aetiology. Nevertheless, the effect of environmental toxins on developmental delay in Sri Lankan children remains an important area for research.

This study was not aimed at identifying the prevalence of GDD. Therefore we propose a multicentre prospective study for a longer period of time, which would assist to determine the severity and the prevalence of GDD in the country. This will be useful for allocation of funds and other resources to improve rehabilitation care and to establish support groups for affected families. It may pave the way for establishment of a 'Global developmental delay registry’ in Sri Lanka.

\section{Acknowledgements}

We thank Prof. Asiri Abeyagunawardena for his continuous support and guidance throughout this research and the parents/guardians of all patients for their enthusiastic participation.

\section{Conclusions}

In the paediatric neurology clinic at the tertiary referral centre, HIE, structural brain abnormalities, post infectious, genetic/chromosomal, embryofetopathy and hypothyroidism were the identified causes of GDD. Aetiology was undetermined with the available clinical details and investigation results in $33.5 \%$.

\section{References}

1. Moeschler JB, Shevell M. Committee on Genetics. Comprehensive evaluation of the child with intellectual disability or global developmental delays. Pediatrics 2014; 134(3): e903-18. https://doi.org/10.1542/peds.2014-1839 PMid: 25157020

2. Shevell M. Global developmental delay and mental retardation or intellectual disability: conceptualization, evaluation, and aetiology. Pediatric Clinics of North America 2008; 55:1071-84. https://doi.org/10.1016/j.pcl.2008.07.010 PMid: 18929052

3. Shevell M, Ashwal S, Donley D, Flint J, Gingold M, Hirtz D, et al. Practice parameter: evaluation of the child with global developmental delay: report of the Quality Standards Subcommittee of the American Academy of Neurology and The Practice Committee of the Child Neurology Society. Neurology 2003; 60(3):367-380. 
https://doi.org/10.1212/01.WNL.0000031

431.81555.16

PMid: 12578916

4. Shevell M. Present conceptualization of early childhood neurodevelopmental disabilities. Journal of Child Neurology 2010; 25:120-6.

https://doi.org/10.1177/088307380933612

PMid: 9738235

5. Carulla LS, Reed GM, Vaez-Azizi LM, Cooper SA, Martinez-Leal R, Bertelli M, et al. Intellectual developmental disorders: towards a new name, definition and framework for "mental retardation/ intellectual disability". ICD-11. World Psychiatry 2011; 10:175-80. https://doi.org/10.1002/j.20515545.2011.t b00045.x

PMid: 21991267 PMCid: PMC3188762

6. Meerding WJ, Bonneux L, Polder JJ, Koopmanschap MA, van der Maas PJ. Demographic and epidemiological determinants of healthcare costs in Netherlands: cost of illness study. British Medical Journal 1998; 317:111. https://doi.org/10.1136/bmj.317.7151.111 PMid: 9657785 PMCid: PMC28601

7. van Karnebeek CDM, Scheper FY, Abeling NG, et al. Aetiology of mental retardation or borderline cognitive delay in 281 children referred to a tertiary care centre: a prospective study. In: van Karnebeek CDM, ed. Mental Retardation: Diagnostic Studies on Aetiology [doctoral thesis]. Amsterdam, Netherlands: Department of Pediatrics/Emma Children's Hospital and Department of Clinical Genetics, Academic Medical Centre, University of Amsterdam. 2002; 75-108.

8. Grandjean P, Landrigan PJ. Neurobehavioral effects of developmental toxicity. Lancet Neurology 2014; 13: 3308.

https://doi.org/10.1016/S14744422(13)702 78-3

9. Shelton JF, Geraghty EM, Tancredi DJ, Delwiche LD, Schmidt RJ, Ritz B, et al. Neurodevelopmental disorders and prenatal residential proximity to agricultural pesticides: The CHARGE Study. Environmental Health Perspectives 2014; 122(10): 1103-9. https://doi.org/10.1289/ehp.1307044

PMid: 24954055 PMCid: PMC4181917

10. van Karnebeek CDM, Shevell M, Zschocke J, Moeschler JB, Stockler S. The metabolic evaluation of the child with an intellectual developmental disorder: Diagnostic algorithm for identification of treatable causes and new digital resource. Molecular Genetics and Metabolism 2014; 111: 428-38.

https://doi.org/10.1016/j.ymgme.2014.01.

011

PMid: 24518794

11. Trasande L, Landrigan PJ, Schechter C. Public health and economic consequences of methyl mercury toxicity to the developing brain. Environmental Health Perspectives 2005; 113(5): 590-6. https://doi.org/10.1289/ehp.7743 PMid: 15866768 PMCid: PMC1257552

12. Moeschler JB, Shevell M, Committee on Genetics. Clinical genetic evaluation of the child with mental retardation or developmental delays. Pediatrics 2006; 117(6): 2304-16.

https://doi.org/10.1542/peds.2006-1006 PMid: 16740881

13. Perera H. Readiness for school entry: a community survey. Public Health 2005; 119: $283-9$.

https://doi.org/10.1016/j.puhe.2004.02.010 PMid: 15733688

14. Department of Census and Statistics, Ministry of National Policies and Economic Affairs. Sri Lanka Labour Demand Survey. 2017; 7-13.

15. Majnemer A, Shevell MI. Diagnostic yield of the neurologic assessment of the developmentally delayed child. Journal of Pediatrics 1995; 127: 193-9. https://doi.org/10.1016/S00223476(95)702 94-6

16. Ozmen M, Tatli B, Aydinli N, Caliskan M, Demirkol M, Kayserilic H. Aetiologic evaluation in 247 children with Global Developmental Delay at Istanbul, Turkey. Journal of Tropical Paediatrics 2005; 51(5):310-3.

https://doi.org/10.1093/tropej/fmi023

PMid: 15967773 
17. Tikaria A, Kabra M, Gupta N, Sapra $\mathrm{S}$, Balakrishnan $\mathrm{P}$, Gulati $\mathrm{S}$, et al. Aetiology of global developmental delay in young children: experience from a tertiary care centre in India. National Medical Journal of India 2010; 23(6):3249.

18. Koul R, Al-Yahmedy M, Al-Futaisi A. Evaluation of children with Global Developmental Delay: A prospective study at Sultan Qaboos University Hospital, Oman. Oman Medical Journal 2012; 27(4): 310-3.

https://doi.org/10.5001/omj.2012.76

PMid: 23071884 PMCid: PMC3464754 